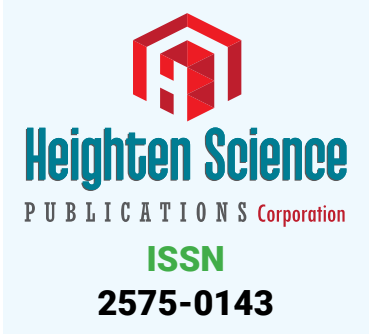

*Address for Correspondence: Dr. Stefan Peters Chair Cardiology, St.Elisabeth Hospital Salzgitter Liebenhaller Str. 20, 38259 Salzgitter, Germany, Email: H.u.S.Peters@t-online.de

Submitted: 27 January 2018

Approved: 01 Febraury 2018

Published: 02 Febraury 2018

Copyright: @ 2018 Peters S. This is an open access article distributed under the Creative Commons Attribution License, which permits unrestricted use, distribution, and reproduction in any medium, provided the original work is properly cited.
Research Article

\section{Electrocardiographic criteria in founder mutations related to Arrhythmogenic cardiomyopathy}

\author{
Stefan Peters* \\ Chair Cardiology St.Elisabeth Hospital Salzgitter, Germany
}

\section{Background}

Founder mutations are rare causes in arrhythmogenic cardiomyopathy including TMEM43 und phospholamban mutations. The incidence is approximately 1\%. P.S358L TMEM43 mutations cause aggressive, in most cases biventricular arrhythmogenic cardiomyopathy [1], with the necessity of primary prophylactic ICD implantation in men and in women $>30$ years for sudden cardiac death prevention. The mutation increases the stiffness of the cell nucleus thus producing the massive loss of cardiomyocytes [2]. P.Arg14del phospholamban mutations cause biventricular arrhythmogenic cardiomyopathy with predominant heart failure, and in some cases, secondary sudden cardiac death [3]. Both founder mutations have characteristic electrocardiographic appearance, together with typical ECG manifestations of arrhythmogenic cardiomyopathy like right precordial T-wave inversions, terminal activation delay and epsilon waves in right precordial leads. Typical ECG manifestations in TMEM43 mutations are poor R-wave progression in right precordial leads (Figure 1), often associated with T-wave inversions in lateral leads [4]. Typical ECG manifestations in phospholamban mutations are low voltage ECG [5], more than complete right bundle branch block [6], epsilon waves in right precordial leads and in lead aVR [7] and right precordial T-wave inversions (Figure 2). Atrial fibrillation occurs frequently.

\section{Case Report}

We followed a family with founder p.S358L TMEM43 mutation with sudden cardiac deaths in two sons. Their sister was diagnosed as having arrhythmogenic right ventricular cardiomyopathy in younger $<30$ years age. The mother was also TMEM43 positive, had no complaints and had no electrocardiographic criteria of arrhythmogenic cardiomyopathy. The ECG of the two sons represented with poor R progression in right precordial leads, coved-type and saddleback type ST segment elevation, retrospectively, and T-wave inversion in lateral leads in one son.

The electrocardiogram of their sister revealed $\mathrm{R}$ wave loss in right precordial leads, terminal activation delay, and no signs of T-wave inversions. At the age of $>30$ years an ICD implantation was performed for primarily prophylactic reasons. The mother remained without any symptoms, and the ECG remained normal.

In 18 cases with typical arrhythmogenic cardiomyopathy low voltage ECG was present, almost always caused by p.Arg14del phospholamban mutation. A genetic testing was nor done. In addition, these 18 cases developed more than complete right bundle branch block, epsilon wave in lead aVR and in 4 cases atrial fibrillation. A single case first developed non-sustained ventricular tachycardia despite $\mathrm{RF}$ ablation with terminal activation delay in ECG, two years later recurrent ventricular fibrillation 

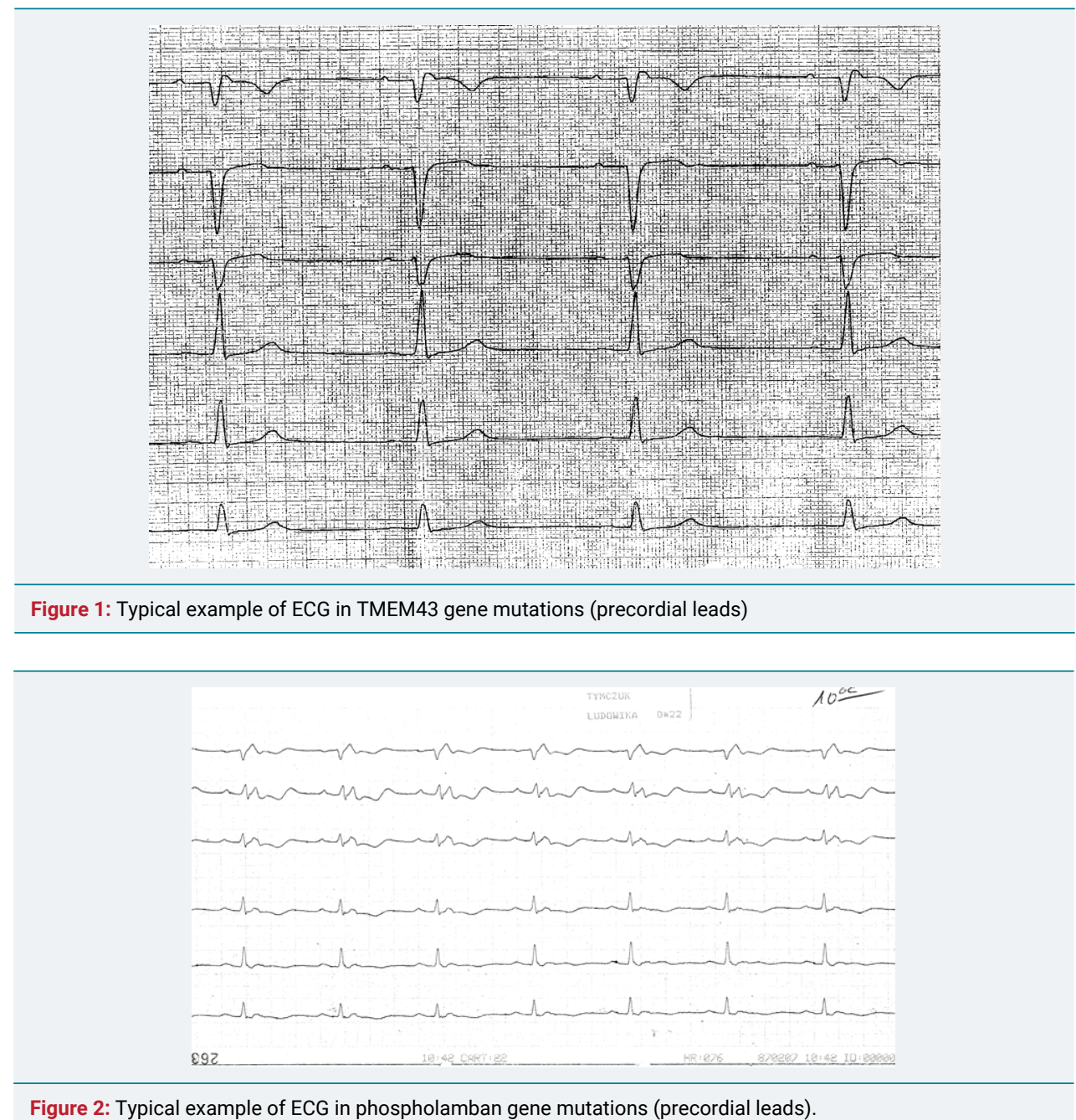

with typical ECG (epsilon waves, right precordial T-wave inversions and ST-segment elevation in right precordial leads), and 6 months later signs of terminal heart failure requiring heart transplantation with the development of low voltage ECG and complete right bundle branch block. In three additional patients the initial ECG was highly typical for arrhythmogenic cardiomyopathy, then developing low voltage ECG, complete right bundle branch block, and epsilon waves in lead aVR. Two additional patients had heart transplantation despite optimisation of heart failure therapy. In 17 cases right and left ventricular dilatation developed after complete right bundle branch block occurred, with decreasing biventricular function. At end stage of the disease it was difficult to decide whether dilated or arrhythmogenic biventricular cardiomyopathy was the right diagnosis.

\section{Data interpretation}

Founder mutations in TMEM43 and phospholamban are characterized by specific ECG abnormalities and specific clinical outcomes. In TMEM43 mutations an aggressive sort of arrhythmogenic cardiomyopathy is present in relation to sudden cardiac death. When TMEM43 mutations was first described in three Newfoundland families several sudden cardiac deaths appeared in the families [8]. In phospholamban mutations heart failure symptoms prevailed. Then histology was analyzed comparing phospholamban and plakophilin-2 mutations a significant higher amount of fibrosis can be seen in phospholamban mutation cases [9], thus developing symptoms of heart failure.

\section{Summary}

In specific founder mutations highly specific ECG abnormalities can be found, in addition to typical changes in arrhythmogenic cardiomyopathy like T-wave inversions 
in right precordial leads, right precordial epsilon waves and terminal activation delay representing localized right precordial QRS prolongation and typical findings in lead $\operatorname{aVR}[10,11]$.

\section{References}

1. Abdel Wahab A, Gardner M, Parkash R, Gray C, Sapp J. Ventricular tachycardia ablation in arrhythmogenic right ventricular cardiomyopathy patients with TMEM43 gene mutations. J Cardiovasc Electrophysiol 2018; 29: 90-97. Ref.: https://goo.gl/479Nom

2. Milting $H$, Klauke $B$, Christensen AH, Müsebeck J, Walhorn V, et al. The TMEM43 Newfoundland mutation p.S358L causing AVRC-5 was imported from Europe and increases the stiffness of the cell nucleus. Eur Heart J 2015; 36: 872-881. Ref.: https://goo.gl/5nuLE3

3. Van Rijsingen IA, van der Zwaag PA, Groeneweg JA, Nannenberg FA, Jongbloed JD, et al. Outcome in phospholamban R14del carriers: results of a large multicentre cohort study. Circ Cardiovasc Genet. 2014; 7: 455-465. Ref.: https://goo.gl/dxya6v

4. Hodgkinson KA, Connors SP, Merner N, Haywood A, Young TL, et al. The natural history of a genetic subtype of arrhythmogenic right ventricular cardiomyopathy caused by a p.S358L mutation in TMEM43. Clin Genet. 2013; 83: 321-331. Ref.: https://goo.gl/ec7JiK

5. Groeneweg JA, van der Zwaag PA, Olde Nordkamp LR, Bikker $\mathrm{H}$, Jongbloed JD, et al. Arrhythmogenic right ventricular dysplasia/cardiomyopathy according to revised 2010 task force criteria with inclusion of non-desmosomal phospholamban mutation carriers. Am J Cardiol. 2013; 112: 11971206. Ref.: https://goo.gl/xLgKxQ

6. Zhang L, Liu L, Kowey PR, Fontaine GH. The electrocardiographic manifestations of arrhythmogenic right ventricular dysplasia. Curr Cardiol Rev. 2014; 10: 237-245. Ref.: https://goo.gl/vgyvwm

7. Peters S. Prognostic value of epsilon waves in lead AVR in arrhythmogenic cardiomyopathy. Int $J$ Cardiol. 2015; 191: 77-78. Ref.: https://goo.gl/7WA3Wm

8. Merner ND, Hodgkinson KA, Haywood AF, Connors S, French VM, et al. Arrhythmogenic right ventricular cardiomyopathy type 5 is a fully penetrant, lethal arrhythmic disorder caused by a missence mutation in the TMEM43 gene. Am J Hum Genet. 2008; 82: 809-821. Ref.: https://goo.gl/sbrfH2

9. Sepehrkhony S, Gho JMIH, van Es R, Harakalova M, de Jonge N, et al. Distinct fibrosis pattern in desmosomal and phospholamban mutation carriers in hereditary cardiomyopathies. Heart Rhythm. 2017; 14: 1024-1032. Ref.: https://goo.gl/MfCGfC

10. Peters S. Clinical importance of lead aVR in arrhythmogenic cardiomyopathy. Int J Cardiol. 2014; 176: 508-509. Ref.: https://goo.gl/x8788E

11. Peters S. Low amplitude of inverted T-waves in lead aVR characterise patients with arrhythmogenic cardiomyopathy. Int J Cardiol. 2016; 220: 202. Ref.: https://goo.gl/HLNytQ 